\title{
Introducing MyPlate in the Curriculum of Nutrition Teaching for Undergraduate Medical and Health Allied Professions of Palestinian Students
}

Nihal Natour ( $\square$ n.natour@najah.edu )

An-Najah National University

Mariam Al-Tell

An-Najah National University

\section{Research Article}

Keywords: MyPlate , American educational tool , United States Department of Agriculture (USDA)

Posted Date: May 13th, 2021

DOI: https://doi.org/10.21203/rs.3.rs-504856/v1

License: (a) (i) This work is licensed under a Creative Commons Attribution 4.0 International License.

Read Full License 


\section{Abstract}

Introduction: MyPlate is an American educational tool that was introduced by United States Department of Agriculture (USDA) as replacement for MyPyramid. It provides the American public with key messages on healthy diet, but was not studied in other populations.

Aims: we aimed to study the acceptance and utility of MyPlate among Palestinian medical and allied health students by introducing the application in the nutrition course which is part of curriculum.

Methods: Electronic survey was distributed on social media and university platforms to Palestinian students at schools of medicine, nursing and pharmacy at Najah University. The survey collected data on demographic variable, obesity, nutritional deficiencies, nutritional problems and use of MyPlate. In addition vegetables use, physical activity information. Data was analyzed using IBM SPSS 21 software.

Results: We included 106 students in the study. $68 \%$ of our study group were females, $58 . \%$ medical students, $44 \%$ were nursing students, and the rest were pharmacy students. $89 \%$ of our students reported using knowing MyPlate, $61 \%$ reported using MyPlate and 79\% reported that they found the use of application easy. The reason for using the application were mainly related to calculating the needed calories and plan a healthy diet. However, our students reported low ability to change their lifestyle accordingly. There was no age difference between users and non-users (19.4 y \pm 0.8 y versus 19.8 y \pm 0.8 y) or BMI $((20.0 \pm 4.6) \mathrm{Kg} / \mathrm{m} 2$ versus $(21.3 \pm 5.8) \mathrm{Kg} / \mathrm{m} 2)$. MyPlate users were more physically active, but there was no difference in physical activity.

Conclusion: MyPlate was very well accepted among our students but they need follow up to improve adherence to healthy lifestyle

\section{Introduction}

In developing countries, malnutrition exists as a burden with obesity and increase in the rate of chronic diseases. The prevalence of obesity among Palestinian young school students ( $13-17 \mathrm{y})$ is $27.8 \%$ in the village of Tarqumia near Hebron (1). Also, in systematic review by Elessi et al, the prevalence of obesity and overweight were $18 \%$ and $30 \%$ in adults and $49 \%$ and $40 \%$ in adults with chronic diseases, indicating the relevance of obesity to chronic diseases(2). Cardiovascular diseases and cancer are the leading causes of death in Occupied Palestinian territories (Opt) according to previous reports(3). In 2000, the prevalence of Diabetes mellitus was 11.5\% in Palestinians who are $25 \mathrm{y}$ or more, and in 2010 it increased to $14.5 \%$ (4). Taken together, this indicates the need for efforts that will slow the health transition that is happening in Opt. It is well-known that diet plays major role in the aforementioned health transition and high prevalence chronic diseases. Lower diet quality is associated with malnutrition, CVD, DM2, cancer and mental related diseases(5). High intake of processed food, saturated fat, trans-fat, sodium and added sugar, along with high calorie associated with processed food is the main reasons behind pathophysiological changes that exacerbate prevalence of chronic diseases along with low intake of fruits, vegetables, fish and sedentary life. In Palestinian territories, very few studies captured trends in 
healthy food intake, whereas there is no clear message from Palestinian Ministry of Health that provides guidelines to healthy eating, despite the presence of many educational campaigns to youth.

In USA, the United States Department of Agriculture (USDA) has provided Americans with food guides since 2016 to help the public making healthy food choices. This was in the form of food Pyramid that was introduced then replaced by MyPlate in June 2011, both of which matched American dietary guidelines which are updated regularly (6). MyPlate is simpler than MyPyramid and it instructs the American public on dietary guidelines by providing simple educational messages(7).

In Palestinian Opt, many universities nowadays provide Medical and Allied health profession education among which is An-Najah National University. An-Najah National University is a public university located mainly in the city of Nablus that provides training in the field of medicine, pharmacy, nutrition, nursing and many allied health profession. Competitive students are enrolled at age around age of $18 \mathrm{y}$ and are given robust theoretical and practical curriculum including clinical training. The official language of teaching is English, and nutrition course is now a compulsory 2 credits in the curriculum of medicine, nursing, pharmacy programs in the preclinical stage. As part of the course we aimed to introduce the updated American dietary guidelines and introducing MyPlate website including tutoring students on how to use it. This paper tries to capture how our students received MyPlate, how they applied it and whether changing their dietary patterns based on this website was feasible.

\section{Methods}

A cross-sectional design was used to evaluate the feasibility of use of MyPlate USDA nutrition education among Palestinians students in the medicine, pharmacy and nursing departments through an electronic data collection tool which was distributed through different social and academic methods that included facebook and Moodle An-Najah electronic education website. The population consisted of all Palestinians students from pharmacy, medicine, and nursing faculties. A convenient sampling method was adopted to reach the determined sample size of $n=106$ students.

The data collection tool was adopted based on a Literature review $(7,8)$. In the study by Radcliff, information on age, diet, use of MyPlate knowledge, use, and easiness, gender, income and smoking and nutritional problems were obtained. It consisted of 3 parts the first one was about the demographic data; the second part was about the about nutritional problems related to weight and anemia. The last part assessed the participants regarding their use of MyPlate and use of vegetables and physical activity

\section{Ethical Consideration:}

The research was conducted in accordance with Declaration of Helsinki and approval from the IRB at An Najah National University was obtained before conducting the study. Agreement of participants was ensured through acceptance of the invitation and answering the questionnaire. 


\section{Consent for Publication:}

was obtained

\section{Statistical analysis:}

Data was summarized using percentages and means \pm SD. Differences of study variables according to categories of MyPlate use, knowledge and easiness were calculated using Chi-square tests if variables were categorical and t-test if variables were continuous. . Data was analyzed by IBM SPSS 21.

\section{Results}

Table 1 provides description of this study population. In total, 106 provided response to the questionnaire and were included in the analysis, most of whom took the nutrition course this semester or in 2020 . The study group were mainly females, MD and nursing students. Very few number of our students were smoking cigarette or hooka. Large proportion of our study group were satisfied with their weight with many having desire to increase it or decrease it. Majority of the study group knew MyPlate application, slightly fewer students used the application in their diet planning and found it easy to use. Among the users of the application, large group used it to plan their diet or find the number of calories they needed. Majority of the students noticed the use of protein instead of meat, but they found that changing their dietary patterns according to MyPlate was not easy. Majority of the study participants take fruits and vegetables between meals, after meals.

Table 2 describe the differences between those who used the application of MyPlate. Majority of smokers were not using myPlate application. The use of MyPlate was not different across categories of gender, weight satisfaction, those who desire to lose weight, or those who desire to gain weight. The use of myPlate was the same between those who have anemia or do not have anemia.

Table 3 describe difference of continuous variables according to knowledge of MyPlate, use of MyPlate, feasibility of MyPlate use. Adults who knew, used, found MyPlate easy had more income and practiced longer duration of physical activity, but other factors such as age, BMI, vegetables intake were not different between users and non-users.

\section{Discussion}

This study involved 106 students from medical, nursing and pharmacy students. Our students reported high acceptance of MyPlate intake. Although MyPlate use was less common among smokers and students with lower household income. Physical activity was higher among students who were interested in MyPlate. However, use of MyPlate was not related to nutritional problems, desire to increase or decrease in weight. Age, obesity and intake of vegetables were not different according to MyPlate use. 
In our study there was a wide acceptance and use of MyPlate despite the fact, students showed it was hard to translate that into practical changes, but they showed high intake of fruits and vegetables. In one study American who are vegetables lovers were more likely to use of MyPlate and find it useful(9). In a study among Americans across USA, 25-45 Y knowledge of MyPlate was not very common, only $20 \%$ reported they knew it, only $30-40 \%$ of those who knew it reported trying to use it and healthy eating index was not related to use of MyPlate(10). Compared to those, our students were given practical tutorial on the use of MyPlate to improve dietary practices which justifies the striking difference in the use of MyPlate between our study and the one by Gray et al. In a study among medical student in King Abdulaziz university, students dietary habits were generally of low quality, smoker students had the poorest dietary habits which, in our study smoker students were less likely willing to use MyPlate to guide their dietary patterns(11). In another study in Dammam, medical students reported eating fast food at high frequency, more than 3 times per week, students in this study reported high consumption of soft drinks and low consumption of fruits and vegetables despite their knowledge of health consequences of such habits(12). Other studies from different countries also reported poor dietary practices among medical students(13). The nursing students in this study had similar rate of acceptance of MyPlate, whereas pharmacy students showed the highest rate of use of MyPlate. In a study in Athens showed better dietary habits than what was reported in American medical students, but still with transition from Mediterranean diet (14). In a study among pharmacy students, Egyptian pharmacy students were more likely practice healthy habits (15). According to author knowledge, medical students at Najah University endure more stressful educational experience and in addition to peer competition for funding which may be translated in form of poorer dietary habits.

USDA recommendation of use of MyPlate not be used alone to change consumer dietary behaviors but rather a reminder of healthy eating and to provide supplementary information. It is well known that not all individuals have access to the internet. For any nutrition education tool to achieve its goals, its information should be easily understood by targeted group. Students have answered that using the website was easy, but converting knowledge to practice was challenging for many. One aspect that could interfere utility of the website is the nutrition literacy among studied group and how well they could interpret nutrition data (16)

Students who have higher income were more likely to benefit from MyPlate. Studies that investigated the relationship between income and dietary habits showed that low-income communities are less likely to eat fruits, vegetables and sweetened drinks which may indicate that low income could be related to poorer dietary habits (17). In our study students with low income were less likely to use MyPlate website. In Opt, could have better access to healthy lifestyle and time to care for their own wellbeing. Besides, Many of our students stay away from family for the period of the study which could pressure to find cheap and fulfilling food without having to look for family. In Opt, according to author knowledge household food security depend on cooking locally purchased meat, grains, and vegetables which provide cheap sources of healthy food, whereas buying junk and fast food for all the family members could be expensive. Also, some students work part-time in addition to study which will make them take wrong choices for food intake. 
Smokers were less likely to use MyPlate to improve their dietary habits. In a study among university students in Palestine, 30\% reported being smokers. Faculty of study and self-reported academic achievement were among the factors that predicted smoking among university students(18). In our study group, only $10 \%$ reported smoking which could be related to the fact, most our study group were

medical or pharmacy students, two faculties with reported highest academic achievements. The smokers were less likely to be using MyPlate. In previous work published in the American Journal of Clinical nutrition, smokers were less likely to consume fruits and vegetables, and more likely to consume meat, alcohol and coffee relative to non-smokers indicating less accountable health seeking behavior among smokers similar to our study(19).

An-Najah National University is a Palestinian non-governmental public university located in Nablus in Northern part of Palestine, it serves 17,807 with 1020 professors in 11 faculties in 2017. It was established in 1977(20). An-Najah University host school of medicine, school of pharmacy and nursing department is part of school of medicine. Every year, schools of medicine and pharmacy receive many students from West Bank, diaspora and Palestinian Israeli.

In this study, USDA dietary guidelines and MyPlate application were well received by our medical and health allied students. Most of students reported knowing it, using it and find it easy to use. Although they found that changing their lifestyle accordingly is challenging. Palestinian students in general reported good intake of fruits and vegetables which could be relevant that Palestinian communities are agricultural communities where traditional food intake is very common.

\section{Abbreviations}

USDA: United States Department of Agriculture; BMI: Body Mass Index

\section{Declarations}

\section{Data Availability}

The datasets generated and/or analyzed during the current study are not publicly available due [being kept confidential for future work] but are available from the corresponding author on reasonable request.

\section{Competing interest}

None

\section{Author Contributions:}


NN designed the study, collected data, analyzed data and wrote part of the manuscript. M.T obtained IRB approval, revised the manuscript

\section{Funding}

None

\section{Ethics Approval and Consent to Participate}

This study was approved by Najah University IRB board. The goals of the study were discussed in social media platforms and participants were asked to fill online survey if they want to participate in the study and filling the form was considered consent to participate in the study.

\section{Consent for publication}

All the study authors read and approved the manuscript for publication

\section{Acknowledgement}

We would like to thank members of the Palestinian society who participated in this study

\section{References}

1. Ghrayeb F, Rusli M, Al Rifai A, Ismail M. Prevalence of overweight and obesity among adolescents in Tarqumia, Palestine. Canadian Journal of Basic and Applied Sciences. 2013;1(1):49-57.

2. Elessi K, Albaraqouni L. Prevalence of obesity and overweight in Palestine: a systematic review. The Lancet. 2019;393:S20.

3. Abu-Rmeileh NM, Husseini A, Giacaman R, Abu-Arqoub O, Hamad M. Peer reviewed: mortality patterns in the West Bank, Palestinian Territories, 1999-2003. Preventing chronic disease. 2008;5(4).

4. Abu-Rmeileh NM, Husseini A, O'Flaherty M, Shoaibi A, Capewell S. Forecasting prevalence of type 2 diabetes mellitus in Palestinians to 2030: validation of a predictive model. The Lancet. 2012;380:S21.

5. Shivappa N. Diet and Chronic Diseases: Is There a Mediating Effect of Inflammation? Nutrients. 2019;11(7):1639.

6. USDA. United States Department of Agriculture, 2011b. http://www.cnpp.usda.gov/ 2020 [

7. Uruakpa F, Moeckly B, Fulford L, Hollister M, Kim S. Awareness and use of MyPlate guidelines in making food choices. Procedia Food Science. 2013;2:180-6. 
8. Radcliff SM. Assessment of the Knowledge and Perception of MyPlate and Dietary Trends amongst Undergraduate College Students: Kent State University; 2019.

9. Wansink B, Kranz S. Who's using MyPlate? Journal of nutrition education and behavior. 2013;45(6):728-32.

10. Vaudin A, Wambogo E, Moshfegh A, Sahyoun NR. Awareness and use of nutrition information predict measured and self-rated diet quality of older adults in the USA. Public Health Nutrition. 2020:1-11.

11. Alzahrani SH, Saeedi AA, Baamer MK, Shalabi AF, Alzahrani AM. Eating habits among medical students at King Abdulaziz University, Jeddah, Saudi Arabia. International journal of general medicine. 2020;13:77.

12. Al-Qahtani MH. Dietary habits of Saudi medical students at University of Dammam. International journal of health sciences. 2016;10(3):353.

13. Vibhute NA, Baad R, Belgaumi U, Kadashetti V, Bommanavar S, Kamate W. Dietary habits amongst medical students: An institution-based study. Journal of family medicine and primary care. 2018;7(6):1464.

14. Evagelou E, Vlachou E, Polikandrioti M, Koutelekos I, Dousis E, Kyritsi E. Exploration of Nursing students' dietary habits. Health Science Journal. 2014;8(4):452.

15. El-Ahmady S, El-Wakeel L. The effects of nutrition awareness and knowledge on health habits and performance among pharmacy students in Egypt. Journal of community health. 2017;42(2):213-20.

16. Castellanos JBJCATDC. Translating MyPlate into Food Selections that Meet Dietary Guidelines Recommendations. Journal of Human Science and Extension. 2016;4(3).

17. Azizan NA, Thangiah N, Su TT, Majid HA. Does a low-income urban population practise healthy dietary habits? International health. 2018;10(2):108-15.

18. Tucktuck M, Ghandour R, Abu-Rmeileh NM. Waterpipe and cigarette tobacco smoking among Palestinian university students: a cross-sectional study. BMC public health. 2018;18(1):1-12.

19. Morabia A, Wynder EL. Dietary habits of smokers, people who never smoked, and exsmokers. The American journal of clinical nutrition. 1990;52(5):933-7.

20. Affouneh SJ, Raba AAA. An emerging model of e-learning in Palestine: The case of An-Najah National University. Creative Education. 2017;8(2):189-201.

\section{Tables}

Due to technical limitations, tables are only available as a download in the Supplemental Files section.

\section{Supplementary Files}

This is a list of supplementary files associated with this preprint. Click to download. 
- Tables.docx

Page 9/9 